УДК $629.783: 621.396 .946: 528.8$

М. Е. ИЛЬЧЕНКО ${ }^{1}$, Т. Н. НАРЫТНИК ${ }^{1,2}$, Б. М. РАССАМАКИН ${ }^{1}$, В. И. ПРИСЯЖНЫЙ ${ }^{3}$, В. В. КАПШТЫК ${ }^{3}$

${ }^{1}$ Национальный технический университет Украины «Киевский Политехнический Институт им. Игоря Сикорского».

${ }^{2}$ СП «Институт электроники и связи Украинской академии наук», Украина

${ }^{3}$ Национальный центр управления и испытаний космических средств, Украина

\title{
СОЗДАНИЕ АРХИТЕКТУРЫ «РАСПРЕДЕЛЕННОГО СПУТНИКА» ДЛЯ НИЗКООРБИТАЛЬНЫХ ИНФОРМАЦИОННО-ТЕЛЕКОММУНИКАЦИОННЫХ СИСТЕМ НА ОСНОВЕ ГРУППИРОВКИ МИКРО- И НАНОСПУТНИКОВ
}

\begin{abstract}
Для низкоорбитальных информационно-телекоммуникационных систем различного назначения предложена архитектура "распределённого спутника», которая базируется на использовании платформ спутников класса микро- и наноспутник и распределения функциональных блоков сложной полезной нагрузки спутников более высокого класса (мини- и мальй спутник) по нескольким функиионально связанным спутникам. Рассмотрены примеры применения архитектуры «распределённого спутника» для радиолокационных систем дистанционного зондирования Земли с синтезированной апертурой низкоорбитальных систем спутниковой связи и спутниковой системы Интернета Вещей.
\end{abstract}

Ключевые слова: распределённый спутник, микро- и наноспутник, дистанционное зондирование земли, спутниковая связь, системы Интернета Вещей, низкая околоземная орбита, информаџионнотелекоммуникационная система.

\section{Введение}

Спираль развития информационно-телекоммуникационных спутниковых систем, сделав полный оборот от систем на низкой круговой орбите до геостационарной орбиты, вновь вернулась к интенсивному использованию низких околоземных орбит (высотой до 1500 км). Растущий интерес к использованию таких орбит обусловлен многими факторами. К ним относятся:

-перспективы внедрения и развития в ближайшее десятилетие Интернета вещей (Internet of Things - IоT) и, построенных с использованием родственных технологий, промышленного интернета вещей (Industrial Internet of Things - IIoT) и интернета вещей для удаленных районов (Remote Internet of Things - RIoT), что обуславливает дальнейшее развитие телекоммуникационных систем для передачи возрастающего трафика этих услуг;

-задачи исследования Земли из космоса для целей научных исследований и экономического использования природных ресурсов, контроля развития и функционирования инфраструктурных проектов, функционирования территориально распределённых промышленных производств, транспортной инфраструктуры всех видов транспорта.
Технологической основой для растущего интереса к использованию низкой околоземной орбиты является технология микроспутников (массой от 10 до 100 кг). Согласно исследованиям компании Euroconsult [1], в этом сегменте рынка ожидается наибольшее количество запусков в ближайшие 10 лет. Характерной чертой микроспутников стало оснащение их полезной нагрузкой, ранее характерной для спутников большей массы, например, мини спутники (масса от 100 до 500 кг) и больше. Эта тенденция отслеживается в сегменте спутников дистанционного зондирования Земли и телекоммуникационных спутников. В последние 5 лет до уровня применимости в системах коммерческого назначения поднялись технологии наноспутников (массой от 1 до 10 кг). Примером может быть финский старт-ап Ісеуе по созданию на базе технологии куб-сат спутника дистанционного зондирования Земли с синтезированной апертурой для мониторинга ледовой обстановки в приполярных широтах [2].

Фактором, существенно ограничивающим дальнейшее внедрение микро- и наноспутников, является их ограниченные возможности по размещению, адаптации, обеспечению электроснабжения и отвода тепла сложной полезной нагрузки. Разрешить это противоречие можно на основе размеще-

() М. Е. Ильченко, Т. Н. Нарытник, Б. М. Рассамакин, В. И. Присяжный, С. В. Капштык 
ния сложной полезной нагрузки на нескольких спутниках, находящихся на одной орбите в непосредственной близости один от другого и функционирующих совместно. Такой подход можно назвать созданием «распределённого спутника».

В качестве примера рассмотрим возможные варианты применения архитектуры «распределённого спутника» в двух сегментах рынка космических информационно-телекоммуникационных систем: дистанционное зондирование Земли и информационно-телекоммуникационные системы.

\section{1. Применение «распределённого спутника» в радиолокационных системах с синтезированной апертурой (SAR-системa)}

Tребования операторов спутниковых SARсистем и потребителей их информации определяют необходимость увеличивать информационное содержание в изображениях SAR, что может быть достигнуто многоканальной работой (поляриметрия, работа в многочастотном режиме), дальнейшее улучшение разрешения по дальности, по азимуту и временным показателям (частота повторной съёмки одной и той же области), а также наблюдение под различными углами (интерферометрия и томография) [4]. Эти требования стимулируют разработку новых технологий, к которым относятся цифровое формирование луча, использование технологии MIMO, антенны с большим отражателем, би- и мультистатические системы.

Дистанционное зондирование Земли.

Использование архитектуры «распределённого спутника» в SAR-системах позволяет реализовать технологию мультистатической радиолокации с «мягкой» интерференционной базой (от 200 м до
1 км) [3]. Для реализации технологии радиолокации с синтезированной апертурой разнесены на отдельные спутники передатчик, для работы которого требуется относительно большая мощность от системы электроснабжения платформы, и приёмная часть. Дополнительным преимуществом такого решения является пространственное разнесение передатчика и приёмника, что позволяет сократить паузы между излучением зондирующих сигналов и, соответственно, улучшить разрешающую способность системы. На рис. 1. представлена схема организации и взаимодействия «распределённого спутника». В состав «распределённого спутника» входят: спутник-передатчик, который является ядром спутникового кластера, и нескольких спутниковприёмников. Спутник-передатчик построен на платформе микроспутника. Спутники-приёмники построены на платформе куб-сат.

Как отмечено в [1], мультистатический режим работы спутниковых SAR-систем имеет следующие преимущества:

- получение высокоточных цифровых карт рельефа местности и трёхмерных изображений объектов;

- возможность одновременного наблюдения объекта под разными ракурсами;

- реализация поляриметрической интерферометрии;

- многократное некогерентное накопление.

Спутник-передатчик выполняет следующие функции:

- управление функционированием «распределённого спутника»;

- формирование и передача (излучение) зондирующего сигнала сложной структуры в используемом частотном диапазоне.

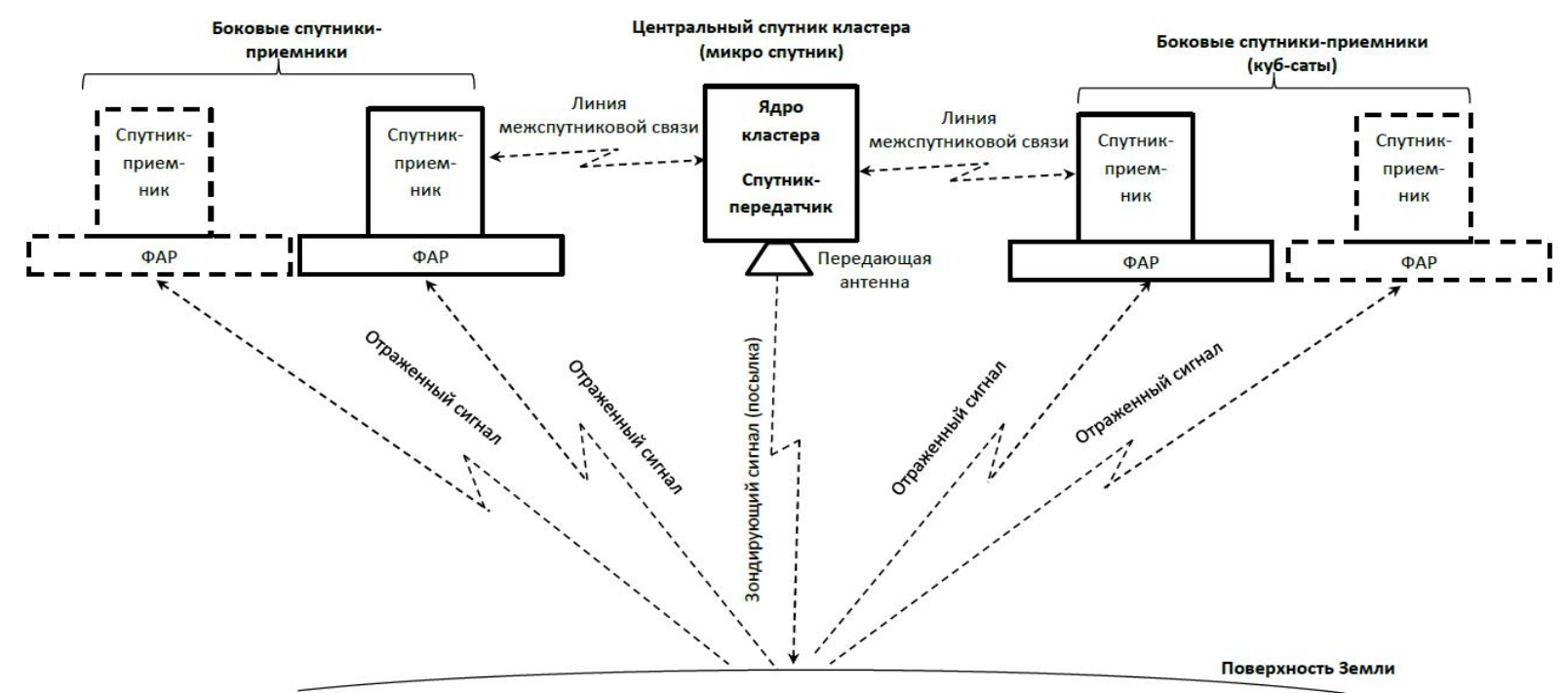

Рис. 1. Применение концепции «распределённого спутника» для задач дистанционного зондирования с синтезированной апертурой 
Передатчик выполняет следующие функции:

- управление функционированием «распределённого спутника»;

- формирование и передача (излучение) зондирующего сигнала сложной структуры в используемом частотном диапазоне;

- проведение измерений взаимного расположения спутника-передатчика и спутников-приёмников с определением наклонной дальности взаимного углового расположения, оценка времени распространения сигнала по линии межспутниковой связи;

- формирование и поддержание местной шкалы времени для синхронизации передачи зондирующего сигнала и приёма отражённого сигнала;

- управление полётом спутника-ретранслятора, приём от наземного комплекса управления команд управления, их обработка, трансляция на наземный комплекс управления телеметрической информации о состоянии спутника-передатчика;

- приём от наземного комплекса управления и трансляция команд управления, адресованных спутникам-приёмникам, приём от спутниковприёмников телеметрической информации и трансляция этой информации на наземный комплекс управления (при штатной эксплуатации);

- приём от спутников-приёмников информационного потока и его трансляция на наземную станцию приёма информации.

Спутник-приёмник выполняет следующие функции:

- приём от спутника-передатчика меток времени с образцом копии переданного зондирующего сигнала;

- приём отражённого сигнала;

- синхронизация шкалы времени для реализации корреляционной обработки принятого сигнала;
- передача цифрового потока комплексной радиоголограммы на наземную станцию приёма информации и/или на спутник-передатчик для дальнейшей ретрансляции на наземную станцию приёма;

- приём по линии межспутниковой связи команд управления и передача телеметрической информации.

Важное место в работе «распределённого спутника» в режиме спутника с синтезированной апертурой занимает межспутниковая радиолиния. Межспутниковая радиолиния является дуплексной радиолинией и предназначена для комплексного решения задач определения геометрических взаимоотношений между спутником-передатчиком и спутниками-приёмниками, передачи результатов первичной корреляционной обработки принятых откликов зондирующего сигнала и передач команднотелеметрической информации. Межспутниковая радиолиния организуется отдельно к каждому спутнику-приёмнику. В отношении каждого спутникаприёмника межспутниковая радиолиния обеспечивает измерение наклонной дальности и определение углов (угол места и азимут в плоскости местного горизонта) на основе моноимпульсного метода слежения. Измерение наклонной дальности позволяет обеспечить синхронизацию передачи и приёма для реализации процедуры корреляционной обработки принятого отклика зондирующего сигнала в спутнике-приёмнике. Измерение геометрии взаимного расположения спутника-передатчика и спутниковприёмников позволяет определить геометрические параметры размещения передающей и приёмной антенн системы.

«Распределённый спутник» работает следующим образом (рис. 2).

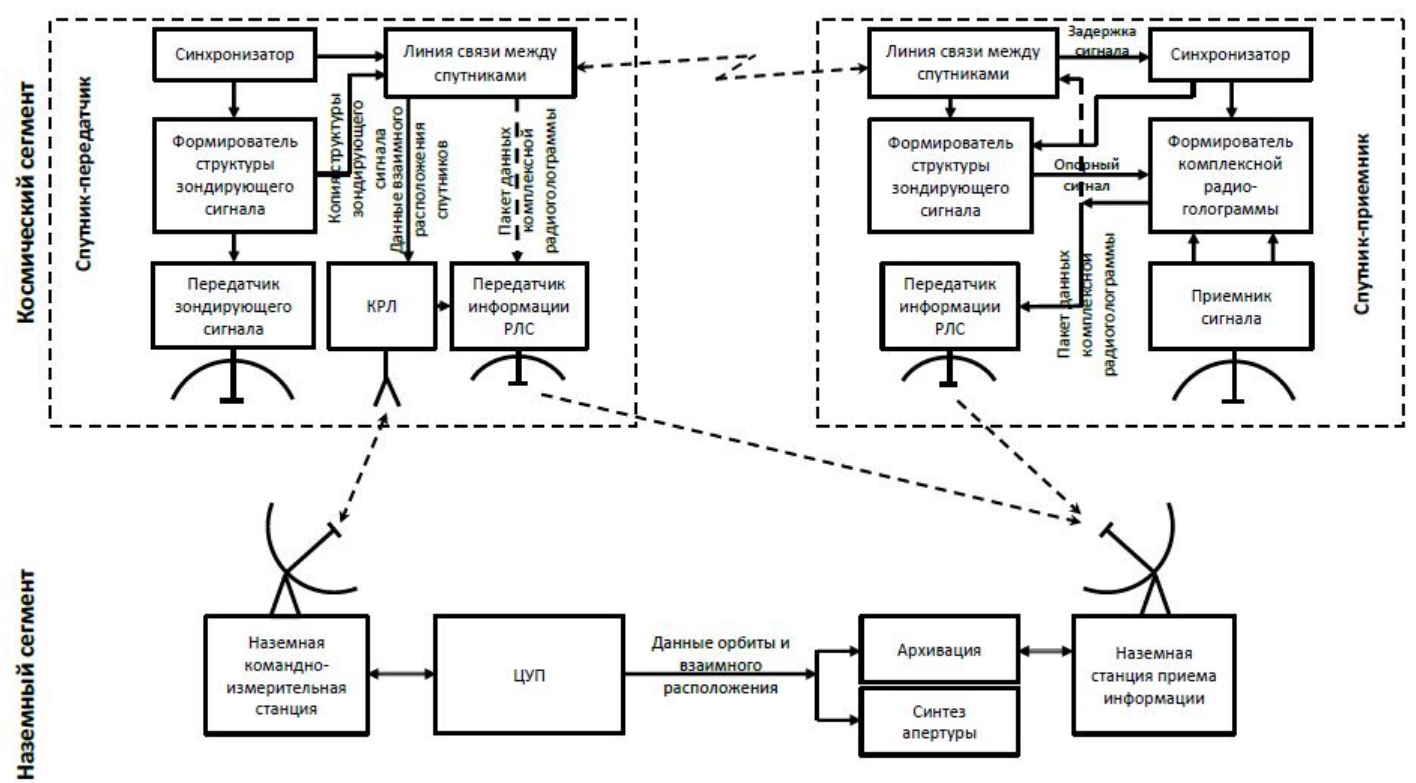

Рис. 2. Структурная схема SAR-системы ДЗ3 с использованием «распределённого спутника» 
Спутник-передатчик формирует зондирующий сигнал сложной формы с заданными авто и взаимнокорреляционными свойствами. Сформированный сигнал излучается передающей антенной спутника в рабочем частотном диапазоне (как правило, диапазоны S, C, X) в направлении поверхности Земли. Ширина диаграммы направленности и ориентация передающей антенны относительно направления надир определяется в соответствии с принятой технологией работы систем с синтезированной апертурой (как правило, $30^{\circ}-45^{\circ}$ ). Копия зондирующего сигнала передаётся спутникам-приёмникам по каналу межспутниковой связи. Данные о длине межспутниковой радиолинии позволяют определить величину задержки сигнала, обусловленную временем распространения сигнала от спутникапередатчика к спутнику-приёмнику, и синхронизировать бортовую шкалу времени спутников в составе «распределённого спутника».

Каждый спутник-приёмник принимает отражённый сигнал и преобразует его в цифровой поток комплексного цифрового сигнала. Поток комплексного цифрового сигнала поступает на дальнейшую обработку в формирователь комплексной радиоголограммы. Спутник-приёмник формирует опорный сигнал, который является копией переданного зондирующего сигнала. Опорный сигнал поступает на формирователь комплексной радиоголограммы, и используется в качестве опорного сигнала при корреляционной обработке. Синхронизацию процедуры корреляционной обработки принятого сигнала обеспечивает синхронизатор.
Результат корреляционной обработки принятого сигнала поступает в виде цифрового потока данных в передатчик информации РЛС для трансляции на наземную станцию приёма информации или в линию межспутниковой связи для передачи на спутник-передатчик, который обеспечивает трансляцию принятого потока на наземную станцию приема информации.

Спутник-передатчик по радиоканалу команднотелеметрической радиолинии (КРЛ) передаёт наземной командно-измерительной станции данные о своём орбитальном положении и взаимном расположении спутника-передатчика и спутников-приёмников. Данные о взаимном расположении спутникапередатчика и спутников-приёмников формирует линия межспутниковой связи. Эти данные используются наземным сегментом при реализации алгоритма синтезирования апертуры с «мягкой» базой.

На рис. 3 приведён алгоритм синтеза SARизображения с использованием быстрого преобразования Фурье для «распределённого спутника». Особенностью алгоритма является распределение вычислительной нагрузки, связанной с обработкой в цифровой форме принятых сигналов и вычисления прямого и обратного быстрого преобразования Фурье над массивами комплексных чисел между космическим и наземным сегментами. Космический сегмент обеспечивает формирование комплексного радиоголографического изображения. Процедура синтеза апертуры возложена на наземный сегмент.

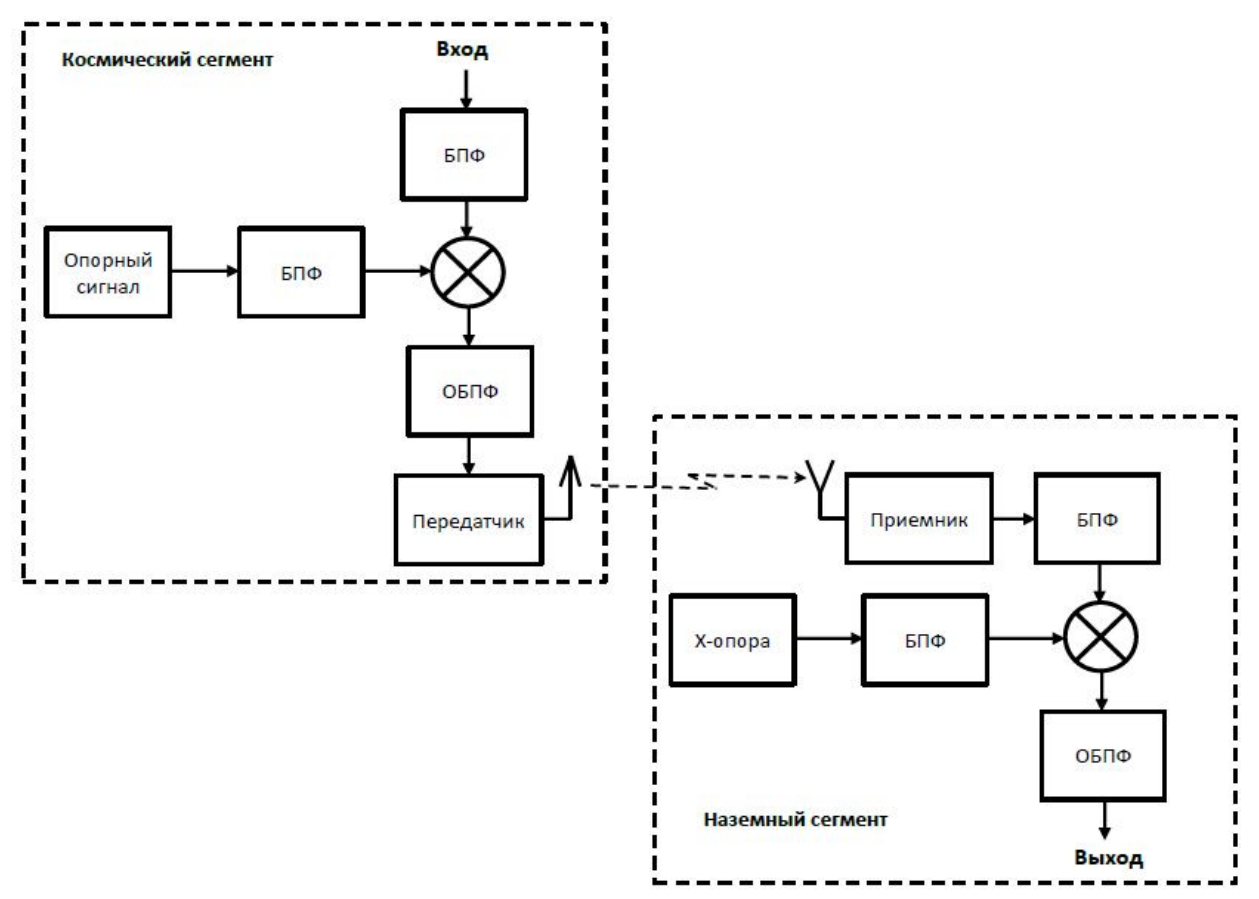

Рис. 3. Алгоритм синтеза радиолокационного изображения с использованием «распределённого спутника» 
Входом алгоритма является цифровой поток комплексных отсчётов принятого сигнала, получаемый на выходе приёмника сигнала (см. рис. 2). Корреляционная обработка принятого сигнала в цифровой форме выполняется методом умножения спектра (в цифровой форме) принятого сигнала со спектром опорного сигнала (см. рис. 3). Формирование спектров принятого и опорного сигналов осуществляется с использованием методов быстрого преобразования Фурье (БПФ). Результат перемножения спектров подвергается обратному преобразованию Фурье с использованием алгоритма обратного быстрого преобразования Фурье (ОБПФ). В результате преобразования формируется цифровое комплексное радиоголографическое изображение, которое передаётся по радиоканалу с космического сегмента на наземный сегмент.

Наземный сегмент на основе информации центра управления полётом (ЦУП) о взаимном расположении спутника-передатчика и спутниковприёмников (см. рис. 2) формирует сигналы «Х-опора» (см. рис. 3). Принятая цифровая последовательность комплексного радиоголографического изображения и сигнал «Х-опора» подвергаются преобразованию Фурье с помощью алгоритма БПФ. После перемножения спектров выполняется обратное преобразование Фурье и формируется итоговое радиолокационное изображение.

\section{2. Применение «распределенного спутника» в телекоммуникационных системах}

В последнее десятилетие вновь возрос интерес операторов и разработчиков систем спутниковой связи к низкоорбитальным системам с использованием мини- и микроспутников. Эффективность функционирования низкоорбитальных систем подтверждена практическим опытом эксплуатации систем «Iridium», «Global Star», «Orbcom».

Сегодня основным форм-фактором спутников для проектируемых низкоорбитальных систем спутниковой являются малый спутник (масса 500-1000 кг) и мини спутник (масса 100-500 кг). Вместе с тем, рассматриваются варианты использования микроспутников (масса 10-100 кг) и куб-сат (масса 1-10 кг). В качестве примера можно привести экспериментальные спутники LEO Vantage 1 и LEO Vantage $2[5,6]$, изготовленные по заказу канадского телекоммуникационного спутникового оператора Telesat для изучения и отработки технологии низкоорбитальной системы широкополосного доступа.

К преимуществам использования спутников форм-фактора куб-сат относятся:

- простота конструкции;
- низкая стоимость;

- унификация и возможность оперативной замены отказавших элементов системы путём замены спутника (куб-сата).

К недостаткам конфигурации системы со спутниками форм-фактора куб-сат относится сложность поддержания конфигурации орбитальной группировки и управления полётом спутников, что обусловлено большим количеством спутников в составе орбитальной группировки.

Фактором, сдерживающим использование спутников типа куб-сат в составе низкоорбитальных систем спутниковой связи, является низкая производительность (мощность) бортовых систем энергоснабжения и отвода тепла. Кроме того, сложной задачей является адаптация телекоммуникационной полезной нагрузки к размерам куб-сата.

Архитектура «распределённого спутника» позволяет распределить функциональные задачи телекоммуникационной полезной нагрузки по нескольким спутникам. На рис. 4 представлен вариант архитектуры низкоорбитальной системы спутниковой связи.

В состав «распределённого спутника» входят корневой спутник и спутники-ретрансляторы. Корневой спутник выполняет следующие функции:

- управление функционированием «распределённого спутника»;

- формирование транспортных потоков DVB-S2, DVB-S2x для передачи в абонентских лучах «распределённого спутника» предоставления услуг конечным потребителям и передача этих потоков на спутники-ретрансляторы для излучения в пользовательских лучах;

- приём от спутников-ретрансляторов информационных потоков DVB-RCS/2 или WiMax от конечных пользователей и их обработка;

- маршрутизация трафика для передачи потоков информации на земные станции сопряжения (GateWay) в лучах станций сопряжения и к соседним «распределённым спутникам» в линии связи между спутниками;

- проведение измерений взаимного расположения корневого спутника и спутников-ретрансляторов с определением наклонной дальности взаимного углового расположения, оценка времени распространения сигнала по линии межспутниковой связи;

- формирование и поддержание местной шкалы времени для синхронизации функционирования спутников в составе «распределённого спутника»;

- управление полётом корневого спутника, приём от наземного комплекса управления команд управления, их обработка, трансляция на наземный 


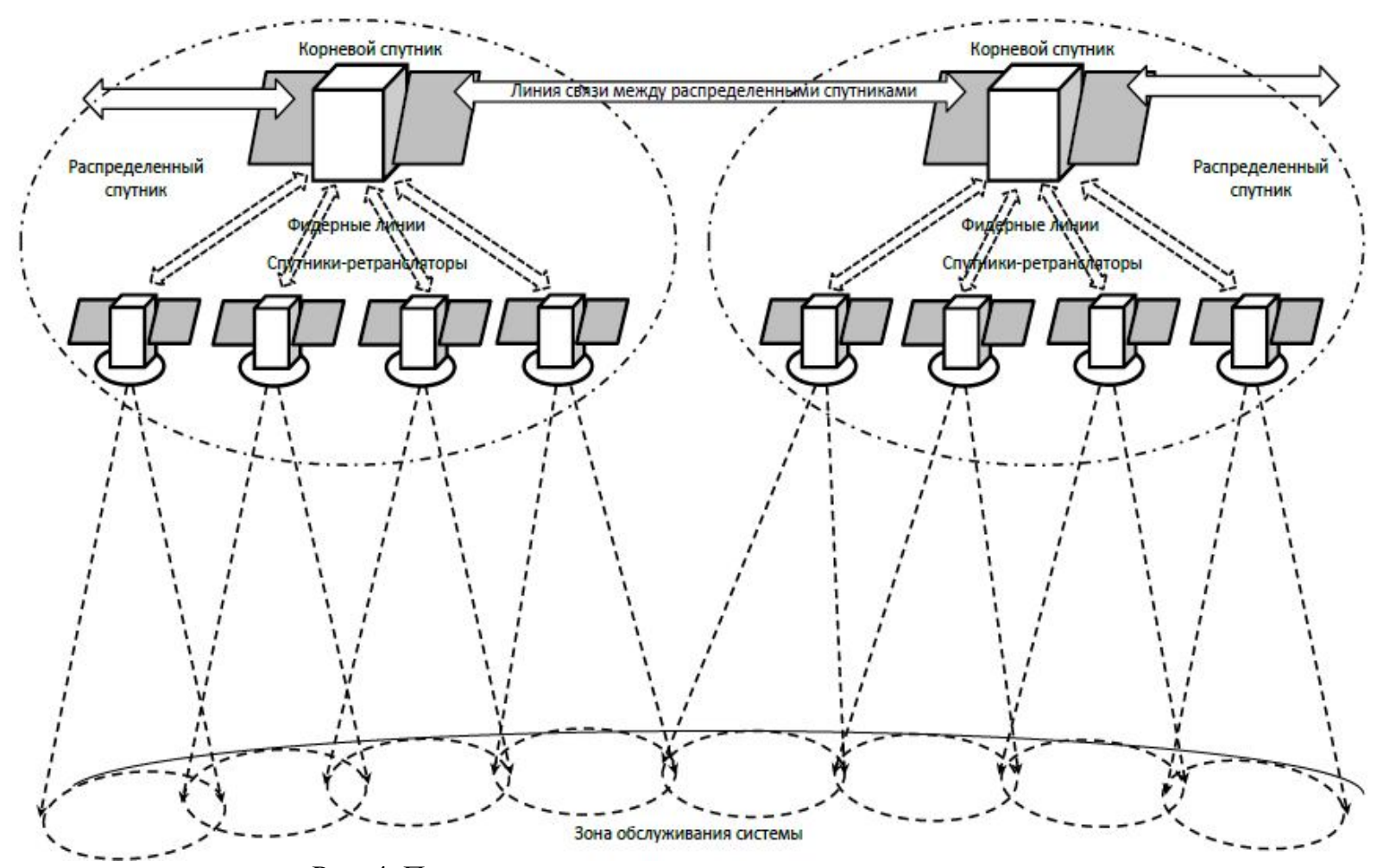

Рис. 4. Применение концепции «распределённого спутника» для низкоорбитальной системы спутниковой связи

комплекс управления телеметрической информации о состоянии корневого спутника;

- приём от наземного комплекса управления и трансляция команд управления, адресованных спутникам-ретрансляторам, приём от спутниковретрансляторов телеметрической информации и трансляция этой информации на наземный комплекс управления (при штатной эксплуатации).

Спутник-ретранслятор выполняет следующие функции:

- формирование в Кu-диапазоне лучей пользователей низкоорбитальной системы для предоставления услуг конечным пользователям низкоорбитальной системы спутниковой связи;

- приём от корневого спутника транспортного потока в формате DVB-S2, DVB-S2x и передача этого потока по лучу пользователей конечным потребителям;

- приём в луче пользователей информации от конечных потребителей в стандарте DVB-RCS/2 или Wi-Max, трансляция принятого потока отражённого сигнала на корневой спутник по линии связи между спутниками в Ка-диапазоне;

- приём от корневого спутника команд управления (в режиме штатной эксплуатации) и передача телеметрической информации для трансляции на наземный комплекс управления;

- приём команд управления от наземного комплекса управления и передача телеметрической информации на командно-измерительную станцию наземного комплекса управления в аварийном режиме (при утрате связи с корневым спутником).

В низкоорбитальной системе спутниковой связи используются два типа линии связи между спутниками:

- линия связи между «распределёнными спутниками» - радиолиния большой протяжённости (до 1000 км и более), которая соединяет корневые спутники высокоскоростными каналами передачи информации и обеспечивает циркуляцию информации в системе спутниковой связи;

- линия связи внутри «распределённого спутника» - радиолиния малой протяжённости (до 1 км), которая обеспечивает циркуляцию информации между корневым спутником и спутникамиретрансляторами «распределённого спутника», а также выполняет измерения взаимного расположения спутников и расстояний между ними.

На рис. 5 приведена схема функционирования распределённого спутника в составе низкоорбитальной системы спутниковой связи (LEO-система). Космический сегмент LEO-системы состоит из нескольких орбитальных плоскостей, имеющих одинаковое количество распределённых спутников, одинаковое наклонение, и отличающихся долготой восходящего узла. В каждой орбитальной плоскости распределённые спутники равномерно размещены с одинаковой относительной истинной аномалией. LEO-система формирует следующие лучи: 


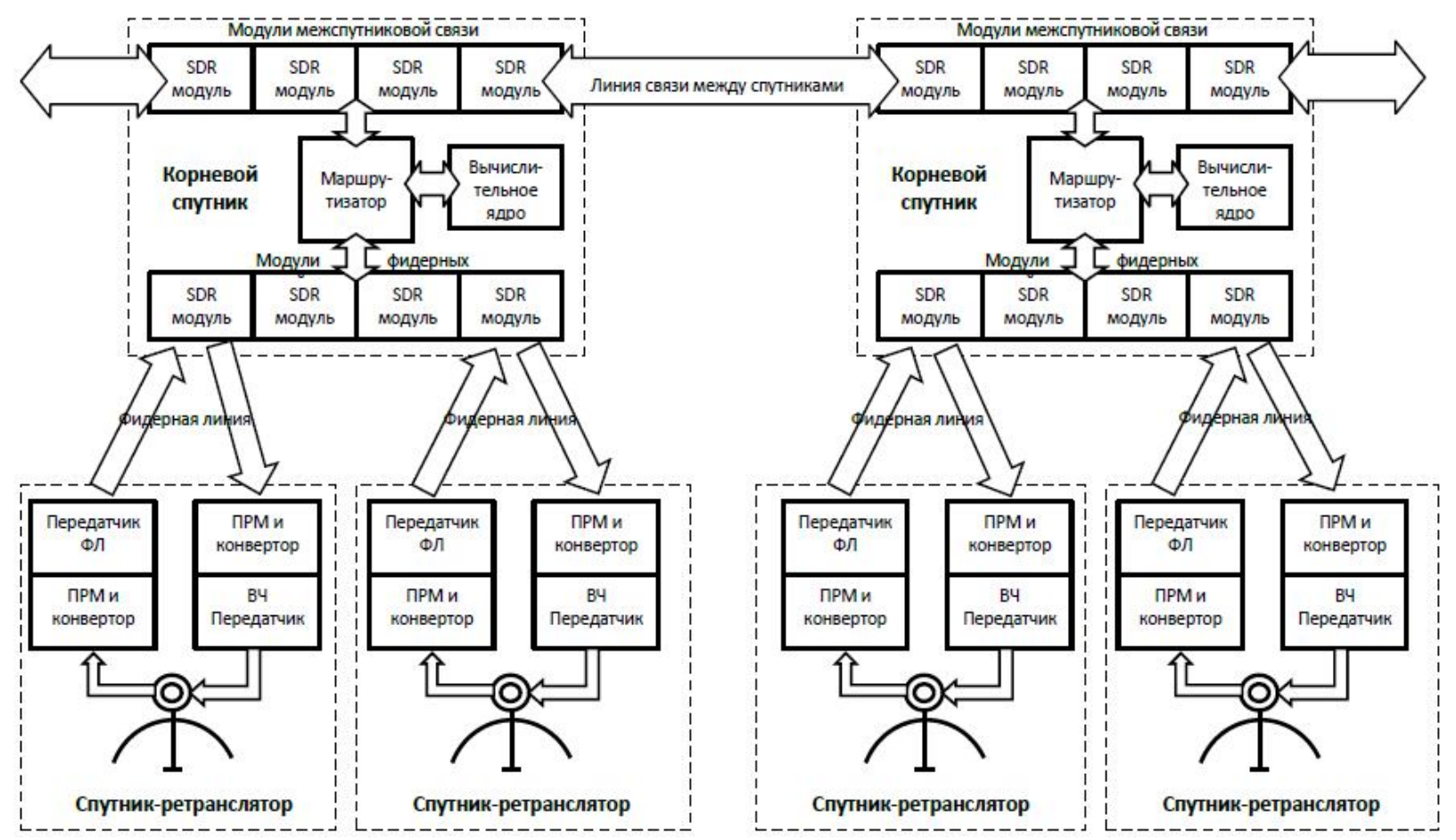

Рис. 5. Схема информационных потоков в распределённом спутнике

- лучи пользователей, предназначенные для обеспечения связи космического сегмента с терминалами конечных пользователей (User's Terminal UT);

- лучи станций сопряжения (шлюзовых станций, Gate Way - GW) для обеспечения связи космического сегмента со станциями сопряжения и через них с наземной сетью связи;

- лучи линий связи между спутниками, предназначенные для обеспечения передачи информации между распределёнными спутниками.

Информационным и интеллектуальным ядром распределённого спутника является корневой спутник. Маршрутизатор полезной нагрузки корневого спутника обеспечивает маршрутизацию информационных потоков согласно статических и динамических таблиц маршрутизации.

Распределённые спутники в LEO-системе связаны между собой линиями связи между спутниками, которые формируют магистральную сеть LEOсистемы. Каждый распределённый спутник связан с двумя соседними распределёнными спутниками в своей орбитальной плоскости и с двумя ближайшими распределёнными спутниками в двух соседних орбитальных плоскостях - по одному в каждой орбитальной плоскости. В составе распределённого спутника функции поддержания линии связи между спутниками возложены на корневой спутник, который оснащён четырьмя модулями программно конфигурируемого радио (SDR модуль) и соответствующими высокочастотными блоками приемо- передатчика (ВЧ модуль). SDR-модули обеспечивают формирование транспортного потока DVB-S2x для передачи информации в магистральной сети LEO-системы в лучах связи между спутниками.

Информационные потоки, предназначенные для передачи в лучах пользователей, формируются маршрутизатором и передаются на интерфейсы SDR-модулей фидерных линий. Фидерные линии обеспечивают соединение корневого спутника со спутниками-ретрансляторами и предназначены для передачи транспортного потока DVB-S2, DVB-S2x к конечным пользователям, и потока DVB-RCS/2 или WiMAX от конечных пользователей. Фидерная линия между корневым спутником и спутникомретранслятором представляет собой внутреннюю линию связи между спутниками в составе распределённого спутника. Эта линия - комбинированная радиолиния, которая обеспечивает дуплексную передачу информации, измерение наклонной дальности и взаимного углового положения между корневым спутником и спутниками-ретрансляторами.

Спутник-ретранслятор формирует луч/лучи пользователей с ограниченной зоной обслуживания. Совокупность лучей, формируемых спутникамиретрансляторами, составляют зону обслуживания LEO-системы. Требования по интегральной зоне обслуживания LEO-системы (географическая зона обслуживания) определяют требования к количеству распределённых спутников в системе в целом. Спутник-ретранслятор излучает в луче пользователей поток DVB-S2, DVB-S2x (прямой канал) и при- 
нимает потоки DVB-RCS/2 или WiMAX от конечных пользователей.

\section{3. Реализация LEO-системы Интернета Вещей (ІоТ) на основе концепции «распределённого спутника»}

Перспективы внедрения и ожидаемое бурное развитие Интернета Вещей (Internet of Things - IoT или, как его называют, Интернета Всего (Internet of Every sing - IoE) ставят перед операторами и разработчиками телекоммуникационных систем задачу подготовки телекоммуникационных решений, адаптированных к особенностям IоT.

Базовой платформой информационной системы IоT выбрана архитектура «туманных вычислений» (Fog Computing - FC). В отличие от архитектуры «облачных вычислений» (Cloud Computing - CC), FC-архитектура ориентирована на приближение вычислительных мощностей как можно ближе к границе сети, где находятся датчики и устройства. Компания Cisco, участник консорциума OpenFog по разработке FC-архитектуры, определила место туманных вычислений в многоуровневой модели (рис. 6, а) [7].

FC-вычисления выполняются на промежуточных уровнях вычислений между оконечными точками и центром обработки данных (ЦОД). В результате анализа объёма трафика многоуровневой информационной архитектуры разработчики консорциума OpenFog пришли к выводу о сокращении объёма передаваемых данных и выполнения вычислительных операций над ними по мере перехода на более высокие иерархические уровни информационной системы [8]. Сокращение объёма передаваемых данных и вычислительных операций сопровождается увеличением интеллектуальной составляющей на более высоких уровнях (см. рис.6, б) [8].

Концепция «распределённого спутника» может быть применена при построении спутниковой системы для предоставления услуг IоT. На рис. 7 приведён вариант «распределённого спутника» с использованием только спутников форм-фактора куб-сат.

Как было рассмотрено ранее ядром «распределённого спутника» является корневой спутник. Корневой спутник выполняет функции маршрутизации и распределения внешних информационных потоков, циркулирующих между «распределёнными спутниками» по магистральной сети LEO-системы, и внутренних информационных потоков внутри «распределённого спутника» между его составными частями. На корневой спутник возложены задачи управления полётом «распределённого спутника», включая трансляцию командной и телеметрической информации к и от спутников-ретрансляторов и других элементов (в режиме штатной эксплуатации), измерение взаимного расположения составных частей «распределённого спутника».

Спутники-ретрансляторы обеспечивают передачу в лучах пользователей транспортного потока DVB-S2, DVB-S2x, и приём потоков DVB-RCS/2, WiMAX от пользователей.

В отличие от ранее рассмотренной структуры, в состав полезной нагрузки спутников-ретрансляторов включены SDR-модули, предназначенные для формирования и обработки транспортных потоков для передачи и приёма информации к и от терминалов конечных пользователей. Для обеспечения связи внутри «распределённого спутника» используется модернизированная сеть WiMAX. Основной причиной модификации протокола WiMAX для использования в составе «распределённого спутника» является необходимость выполнения измерений взаимного расположения спутников в составе «распределённого спутника» и одновременно с измерениями передачи информации для информационного обмена.

Архитектура «распределённого спутника» позволяет реализовать в космическом сегменте LEOсистемы FC-архитектуру. Для этого в состав «распределённого спутника» включается отдельный спутник-вычислитель, задачей которого является

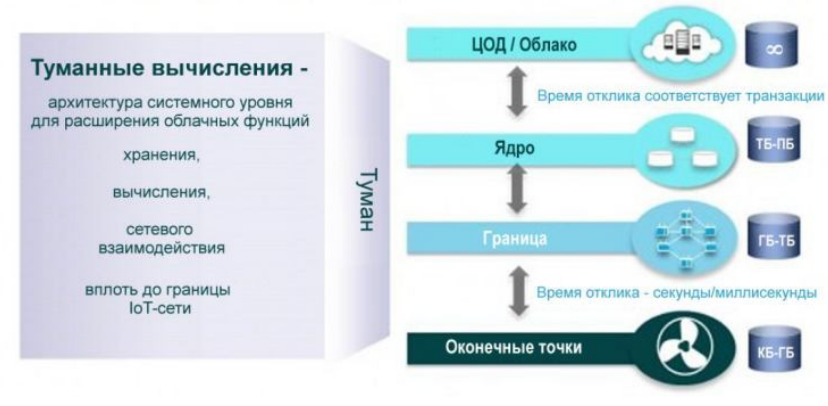

a

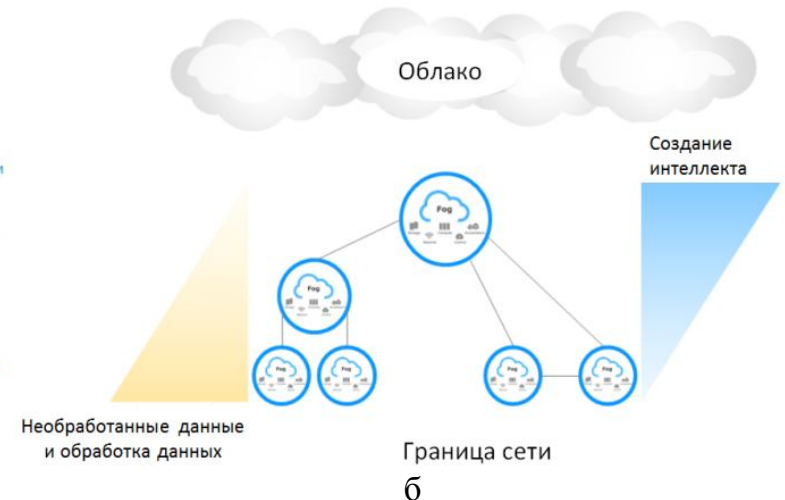

6

Рис. 6. «Туманные вычисления» в иерархической многоуровневой модели вычислений ІоТ 


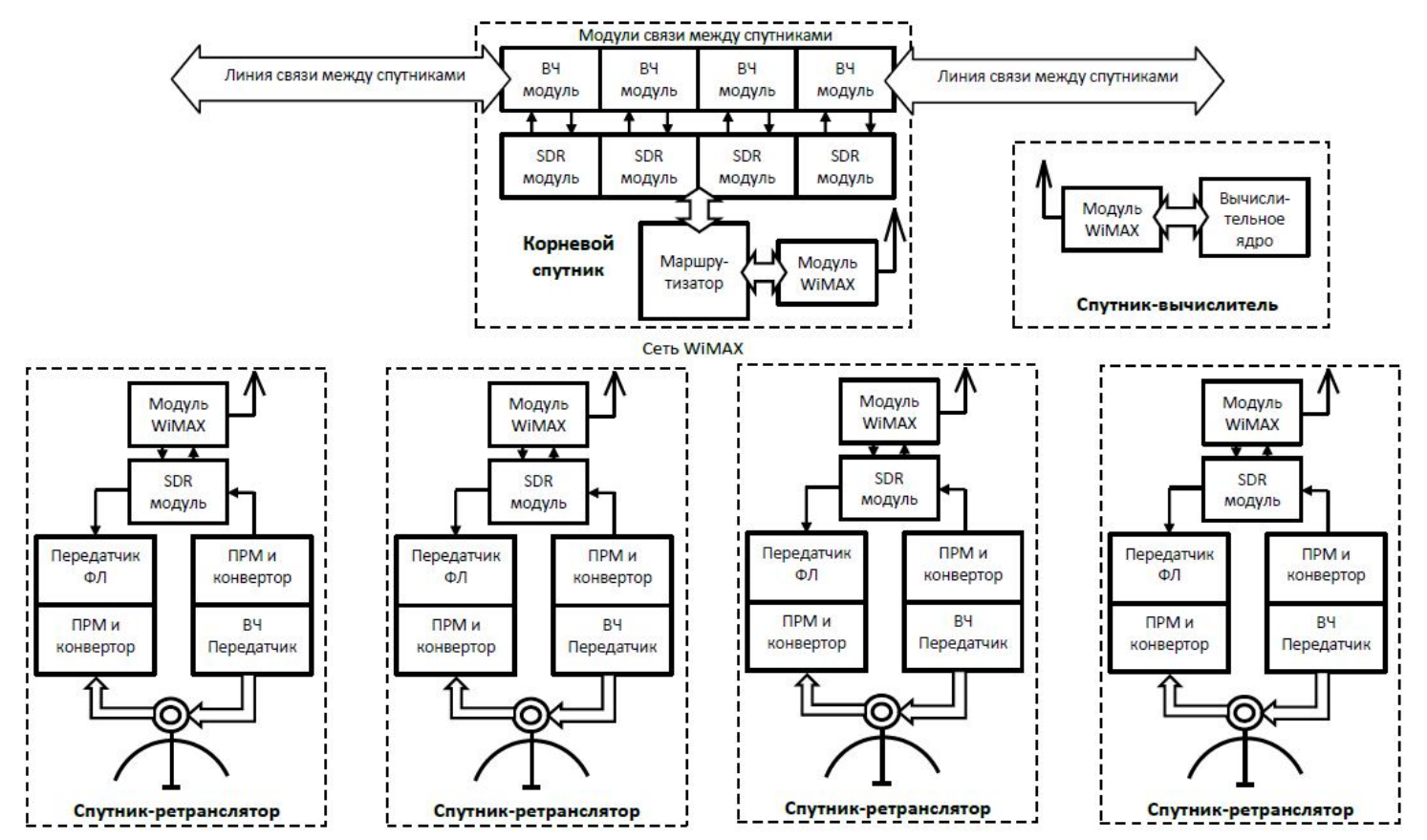

Рис. 7. Вариант «распределённого спутника» для LEO-системы IоT с использованием куб-сат

выполнение необходимых вычислений для обеспечения функционирования устройств ІоТ в пределах зоны обслуживания «распределённого спутника». Полезной нагрузкой куб-сата, выполняющего роль спутника-вычислителя, является бортовой компьютер. В случае недостаточности вычислительной мощности для обслуживания ІоТ устройств, могут быть подключены вычислительные мощности других «распределённых спутников» с использованием линий связи между спутниками и алгоритмов распределения вычислительной нагрузки в распределённой вычислительной сети.

Важной задачей является поддержание базы данных, содержащей результаты обработки информации устройств ІоТ и проведения необходимых вычислений. Данная база по природе ІоТ является локальной и поэтому должна быть привязана к району размещения IоT устройств. Учитывая постоянное движение группировки LEO-спутников относительно поверхности Земли, в LEO-системе формируется распределённая база данных с локализацией к районам размещения ІоТ-устройств и потребителей. Сегмент базы данных, привязанный к конкретному району, загружается по линиям связи между спутниками в память спутника-вычислителя по мере приближения «распределённого спутника» к выбранному району размещения ІоТ-устройств и потребителей ІоТ-услуг. При прохождении выбранного района актуализированный по результатам обработки информации и проведения вычислений для ІоТ-устройств сегмент базы данных передаётся по линиям связи между спутниками следующему «распределённому спутнику», который будет обслуживать выбранный район.

\section{Заключение}

В основе архитектуры «распределённого спутника» лежит распределение функциональных и конструктивных элементов сложной полезной нагрузки современных спутников класса малый спутник или мини спутник по нескольким спутникам классом ниже: микроспутник и наноспутник. Архитектура «распределённого спутника» позволяет использовать спутники класса микроспутник и наноспутник (куб-сат) для создания сложных информационнотелекоммуникационных систем космического базирования, в частности систем дистанционного зондирования земли радиолокационного типа с синтезированной апертурой и систем связи и широкополосного доступа, в том числе систем Интернета вещей. Учитывая нелинейную зависимость стоимости изготовления спутника от его массы, использование платформ микроспутников массой до 100 кг и наноспутников массой до 10 кг создаёт условия для снижения стоимости решения функциональной задачи низкоорбитальной информационной системы. Разнесение функциональных элементов целевой полезной нагрузки системы по нескольким физически обособленным элементам позволяет упросить восстановление работоспособности системы и создать условия для совершенствования системы в процессе эксплуатации. 


\section{Литература}

1. Prospects for the Small Satellite Market. A Euroconsult Executive Report [Electronic resource]. Access mode: http://euroconsultec.com/research/smallsats-2017-brochure.pdf. 16.12.2017.

2. Foust, Jeff. Iceye raises $\$ 13$ million for radar microsatellites [Electronic resource] / Jeff Foust. Access mode: http://spacenews.com/iceye-raises-13million-for-radar-microsatellites/-24.07.2017.

3. Радиолокационные системы землеобзора космического базирования [Текст] / В. С. Верба, Л. Б. Неронский, И. Г. Осипов, В. Э. Турук ; под ред. B. C. Вербы. - М. : Радиотехника, 2010-680 c.

4. A Tutorial on Synthetic Aperture Radar [Text] / Alberto Moreira, Pau Prats-Iraola, Marwan Younis, Gerhard Krieger, Irena Hajnsek, Konstantinos P. Papathanassiou // IEEE Geoscience and Remote Sensing Magazine. - 2013. - Vol. 1, Iss. 1. - P. 6-43. DOI: 10.1109/MGRS.2013.2248301.

5. LEO Vantage 1 [Electronic resource] / Gunter's Space Page. - Access mode: http://space.skyrocket.de/doc_sdat/leo-vantage-1.htm. 15.01.2018.

6. LEO Vantage 2 Satellite. [Electronic resource] / Space News and Beyond. - Access mode: http://spaceflight101.com/meteor-m-2-1/leo-vantage-2/. -15.01 .2018 .

7. Крани, Мачек. Туманные вычисления спускают облачный функиионал на землю [Electronic resource] / Мачек Крани // Caüm Cisco. - Access mode: $\quad$ https://www.cisco.com/c/ru_ru/about/press/ press-releases/2015/08-13d.html. - 15.01.2018.

8. OpenFog Reference Architecture for Fog Computing. Produced by the OpenFog Consortium Architecture Working Group. February 2017. OPFRA001.020817 [Electronic resource]. - Access mode: https://www.openfogconsortium.org/wp-content/ uploads/OpenFog_Reference_Architecture_2_09_17FINAL.pdf. - 15.01.2018.

\section{References}

1. Prospects for the Small Satellite Market. A Euroconsult Executive Report. Available at: http://euroconsult-ec.com/research/smallsats-2017brochure.pdf (accessed 16.12.2017).

2. Foust, Jeff. Iceye raises $\$ 13$ million for radar microsatellites. Available at: http://spacenews.com/ iceye-raises-13-million-for-radar-microsatellites/ (accessed 24.07.2017).

3. Verba, V. S., Neronskyi, L. B., Osypov, Y. H., Turuk, V. Э. Radiolokacionnye sistemy zemleobzora kosmicheskogo bazirovanija [Earth-based space survey radar systems]. Moskow, Radiotehnika Publ., 2010. $680 \mathrm{p}$.

4. Moreira, A., Prats-Iraola, P., Younis, M., Krieger, G., Hajnsek, I., Papathanassiou, K. P. A Tutorial on Synthetic Aperture Radar. IEEE Geoscience and Remote Sensing Magazine, 2013, vol. 1, iss. 1, pp. 6-43. DOI: 10.1109/MGRS.2013.2248301.

5. LEO Vantage 1. Gunter's Space Page. Available at: http://space.skyrocket.de/doc_sdat/leo-vantage1.htm (accessed 15.01.2018).

6. LEO Vantage 2 Satellite. Space News and Beyond. Available at: http://spaceflight101.com/meteor-m2-1/leo-vantage-2/ (accessed 15.01.2018).

7. Kranz, Maciej. Tumannye vychislenija spuskajut oblachnyj funkcional na zemlju [Misty calculations lower the cloud functionality to the ground]. Available at: https://www.cisco.com/c/ru_ru/about/ press/press-releases/2015/0813d.html (accessed 15.01.2018).

8. OpenFog Reference Architecture for Fog Computing. Produced by the OpenFog Consortium Architecture Working Group. February 2017. OPFRA001.020817 Available at: https://www. openfogconsortium.org/wp-content/uploads/OpenFog_ Reference_Architecture_2_09_17-FINAL.pdf. (accessed 15.01.2018).

Поступила в редакциию 12.02.2018, рассмотрена на редколлегии 4.04.2018

\section{СТВОРЕННЯ АРХІТЕКТУРИ «РОЗПОДІЛЕНОГО СУПУТНИКА» ДЛЯ НИЗЬКООРБІТАЛЬНИХ ІНФОРМАЦЙНО-ТЕЛЕКОМУНІКАЦЙНИХ СИСТЕМ НА ОСНОВІ УГРУПОВАННЯ МІКРО- І НАНОСУПУТНИКІВ}

\section{М. Ю. Ільченко, Т. Н. Наритник, Б. М. Рассамакін, В. І. Присяжний, С. В. Капштик}

Для низькоорбітальних інформаційних систем різного призначення запропонована архітектура «розподіленого супутника», яка базується на використанні платформ супутників класу мікро- і наносупутник i розподілу функціональних блоків складного корисного навантаження супутників більш високого класу (міні супутник і малий супутник) за кількома функціонально пов'язаними супутниками. Розглянуто приклади застосування архітектури «розподіленого супутника» для радіолокаційних систем дистанційного зондування Землі з синтезованою апертурою, низькоорбітальних систем супутникового зв'язку і супутникової системи Інтернету Речей.

Ключові слова: розподілений супутник, мікро- і наносупутник, дистанційне зондування землі, супутниковий зв'язок, системи Інтернету Речей, низька навколоземна орбіта, інформаційно-телекомунікаційна система. 


\section{CREATION OF THE ARCHITECTURE OF "DISTRIBUTED SATELLITE" \\ FOR LOW-ORBITAL INFORMATION-TELECOMMUNICATION SYSTEMS BASED ON THE GROUPING OF MICRO AND NANO SATELLITES}

\section{Ilchenko, T. Narytnik, B. Rassamakin, V. Prisyazhny, S. Kapshtik}

Presented are the results of an analysis of the growing interest in the use of low Earth orbits (up to $1500 \mathrm{~km}$ high) for the introduction and development of the Internet of things (Internet of Things - IoT). Industrial Internet of things (Industrial Internet of Things-IIoT). Internet of things for remote areas (Remote Internet of Things - RioT, for the purposes of scientific research and economic use of natural resources, control of the development and operation of infrastructure projects, the operation of territorially distributed industrial production, transport infrastructure.

Factors significantly limiting the further introduction of micro and nano satellites are given. The authors proposed to resolve this contradiction on the basis of the developed concept of creating the architecture of a "distributed satellite". As an example, the article considers possible applications of the distributed satellite architecture in two segments of the space information systems market: remote sensing of the Earth and telecommunication systems. The application of the "distributed satellite" in radar systems with synthesized aperture (SAR-system) was considered taking into account the requirements of the operators of satellite SAR-systems and consumers of their information. It is shown. that the use of the "distributed satellite" architecture in SAR-systems also makes it possible to realize the technology of multi-static radar with a "soft" interference base (from $200 \mathrm{~m}$ to $1 \mathrm{~km}$ ). The scheme of organization and interaction of the "distributed satellite" in the satellite-transmitter on the platform of the micro satellite, which is the core of the satellite cluster, and several satellites-receivers on the cube-sat platform is presented. The functions performed by the satellite-transmitter, the inter-satellite radio link and the satellite-receiver are considered in detail. The work of the "distributed satellite" is illustrated by the presented structural diagram of the SAR-system for remote sensing of the Earth, a version of the architecture of the low-orbit satellite communication system and the scheme for constructing a satellite system for the provision of IoT services.

In conclusion, it is noted that the architecture of the "distributed satellite" makes it possible to effectively use satellites of the class of micro/nano satellite (cube-sat) to create complex space-based information and telecommunication systems.

Keywords: distributed satellite, micro/nano satellite, remote sensing of the earth, satellite communications, Internet systems Things, low Earth orbit, information and telecommunication system.

Ильченко Михаил Ефимович - д-р техн. наук, проф., академик Национальной академии наук Украины, заслуженный деятель науки и техники, лауреат Государственных премий в области науки и техники Украинской ССР, СССР и Украины, проректор по научной работе НТУУ КПИ им. Игоря Сикорского, e-mail: ilch@kpi.ua.

Нарытник Теодор Николаевич - канд. техн. наук, академик Украинской академии наук, лауреат Государственных премий в области науки и техники Украинской ССР, СССР и Украины, директор СП «Институт электроники и связи Украинской академии наук»; вед. науч. сотр., проф. каф. телекоммуникаций Института телекоммуникационных систем НТУУ «КПИ им. Игоря Сикорского», е-mail: director@mitris.com.

Рассамакин Борис Михайлович - канд. техн. наук, ст. науч. сотр., зав. лаб. наноспутниковых технологий НТУУ КПИ им. Игоря Сикорского, e-mail: office@lab-hp.kiev.ua.

Присяжный Владимир Ильич - канд. техн. наук, ст. науч. сотр., лауреат Государственной премии Украины в области науки и техники, начальник Национального Центра Управления и Испытаний Космических Средств, e-mail: ncuvkz@spacecenter.gov.ua.

Капштык Сергей Владимирович - канд. техн. наук, помощник начальника Национального Центра Управления и Испытаний Космических Средств, e-mail: sergii.kapshtyk@gmail.com.

Ilchenko Mykhailo - DrS on Engineering, professor, academician of National Academy of Sciences of Ukraine, Honored Scientist of Ukraine, Laureate of State Prize of the Ukrainian SSR, the USSR and Ukraine in science technology, vice-rector on scientific work of NTUU "KPI" named after Igor Sikorsky", e-mail: $\underline{\text { ilch@,kpi.ua }}$

Narytnyk Teodore - PhD, Academician of the Ukrainian Academy of Sciences; Laureate of State Prizes in the field of science and technology of the Ukrainian SSR, USSR and Ukraine, director of the Joint venture "Institute of Electronics and Communications of the Ukrainian Academy of Sciences", Leading Research Associate, Professor of the Telecommunications Department of the Institute of Telecommunication Systems of NTUU "KPI" named after Igor Sikorsky", e-mail: director@mitris.com.

Rassamakin Boris - PhD, Senior Researcher, Head laboratory of nanosatellite technologies of NTUU "KPI" named after Igor Sikorsky", e-mail: office@lab-hp.kiev.ua.

Prisyazhny Vladimir - PhD, Laureate of State Prizes in the field of science and technology of the Ukraine, Head of the National Space Facility Control and Testing Center, e-mail ncuvkz@spacecenter.gov.ua.

Kapshtyk Sergii - PhD, assistant to Head of the National Space Facility Control and Testing Center, e-mail sergii.kapshtyk@gmail.com. 